\title{
Vaginal progesterone after tocolytic therapy in threatened preterm labour
}

\author{
Aparajita Ashok Mishra, Shilpa N. Chaudhari*
}

Department of Obstetrics and Gynecology, Smt. Kashibai Navale Medical College and General Hospital, Pune, Maharashtra, India

Received: 19 May 2020

Accepted: 29 June 2020

*Correspondence:

Dr. Shilpa N. Chaudhari,

E-mail: drshilpachaudhari15671@gmail.com

Copyright: () the author(s), publisher and licensee Medip Academy. This is an open-access article distributed under the terms of the Creative Commons Attribution Non-Commercial License, which permits unrestricted non-commercial use, distribution, and reproduction in any medium, provided the original work is properly cited.

\begin{abstract}
Background: Currently preterm labour is one of the most challenging problem faced by both obstetricians and perinatologists, this episode in the course of woman's pregnancy takes a heavy tool for perinatal mortality which accounts for approximately 50-75\%. The incidence of preterm labour is estimated to be 5-10\% of all pregnancies.

Methods: It was a prospective randomize control trail over a period of 3 year at department of obstetrics and gynecology, tertiary care hospital Pune, Maharashtra, India. Total 100 subjects were randomized into two groups with group one receiving vaginal micronized progesterone and group two control group receiving only tocolytics and steroids. Subsequently authors compared the safety and efficacy of vaginal micronized progesterone versus placebo as a maintenance therapy in preventing preterm labour.

Results: This analysis showed that women who randomized to progesterone prophylaxis had a significantly increase in duration of pregnancy. The mean of birthweight in Group A and Group B was $2963 \pm 36$ gm and $2567 \pm 49$ gm and respectively which confirmed the positive effects of progesterone on increasing infants' weights at birth.

Conclusions: Authors concluded that progesterone therapy had acceptable efficacy in the prevention of preterm labor in terms of prolongation of delivery and by increasing gestational age at delivery.
\end{abstract}

Keywords: Threatened preterm labour, Tocolysis, Vaginal progesterone

\section{INTRODUCTION}

Over the past 50 years, extensive research has been conducted for preventing, predicting and optimizing the outcome of patients with preterm labour. Despite the exhaustive efforts, the incidence of preterm labour has increased in recent years.

Currently preterm labour is one of the most challenging problems faced by both obstetricians and perinatologists, as this episode in the course of woman's pregnancy takes a heavy tool for perinatal mortality which accounts for approximately 50- $75 \% .^{1}$ The incidence of preterm labour is estimated to be $5-10 \%$ of all pregnancies, but there is some difference with different population and variable on socioeconomic status. ${ }^{2}$

The progesterone is essential for the maintenance and prolongation of pregnancy., ${ }^{3,4}$ Delaying delivery reduces the rate of long-term morbidity by facilitating maturity of vital organs, helps in optimum action of the administered glucocorticoids, helps in transfer to higher centre with NICU facilities.

There are no accurate recent worldwide data, but estimates of preterm birth rates range from 5\% in developed countries to $25 \%$ in developing countries. The preterm delivery rate has been relatively stable at $5-10 \%$ 
in developed countries for many years. Incidence of preterm labour has increased in recent past because of the medically induced prematurity (either because of medical conditions or obstetric complication).

So different trials have been done to show the efficacy and safety of progesterone in prevention of recurrent preterm birth since $1960 .{ }^{5-7}$ Progesterone can be administered via oral capsule, vaginal gel or suppository, or intramuscularly.., 9

Oral administration has better patient compliance but there is variability in the plasma concentrations of the drug due to personal variation in gastric filling and enterohepatic circulation, also this route can be associated with side effects such as nausea, headache, sleepiness, etc. $^{10,11}$

The vaginal route results in higher local concentrations in uterus but its blood levels are low, while progesterone administered intramuscularly has optimal blood levels. ${ }^{12}$ Injectable form of $17 \alpha$ hydroxy progesterone (Mekena) has been approved by FDA to reduce the risk of preterm labour before 37 weeks of gestation. ${ }^{13}$

So, this study is to compare the safety and efficacy of micronized vaginal progesterone versus placebo as maintenance therapy to prevent preterm labour in singleton pregnancy.

\section{METHODS}

It was a prospective randomize control trail. All 100 subjects were randomized into two groups using simple randomization technique with group A received tocolysis, steroids and vaginal micronized progesterone and group B control group receiving only tocolytics and steroids. All preterm pregnancy of more than 20 weeks is considered in this study. Initial nifedipine $10 \mathrm{mg}, 4$ tablets 15 min apart is given for tocolytic activity for 48 hours. Injection betamethasone $12 \mathrm{mg}$ I.M. 2 doses in a duration of 24 hours apart is given for fetal lung maturity.

Patients are followed-up on OPD basis at regular interval on antenatal visits, by thorough history taking, laboratory investigations, regular antenatal examination. Serial USG to monitor gestation age and growth.

Subsequently authors compared the safety and efficacy of vaginal progesterone versus placebo as a maintenance therapy in preventing preterm labour and analysed maternal factors like prolongation of labour, rate of preterm delivery, gestational age at delivery, mode of delivery, satisfaction of the participants and adverse effects of the drugs was evaluated.

Fetal factors like birth weight, mortality, NICU admissions, Apgar score, neonatal mortality or morbidity, no of days of NICU admission was evaluated.

\section{Statistical analysis}

The data so collected was presented with graphical representation, in tabular form with graphical representation. Statistical analysis was performed with SPSS software and t-test was used for continuous data and Pearson chi-square test for discrete data.

\section{RESULTS}

Of 50 cases studied in Group A, 7 (14.0\%) had age between 18-20 years, $18(36.0 \%)$ had age between $21-25$ years, $17(34.0 \%)$ had age between 26-30 years and 8 (16.0\%) had age between $31-35$ years. Of 50 cases studied in Group B, 7 (14.0\%) had age between 18-20 years, $19(38.0 \%)$ had age between $21-25$ years, 16 $(32.0 \%)$ had age between $26-30$ years and $8(16.0 \%)$ had age between 31-35 years. The age distribution of cases studied did not differ significantly between two study groups.

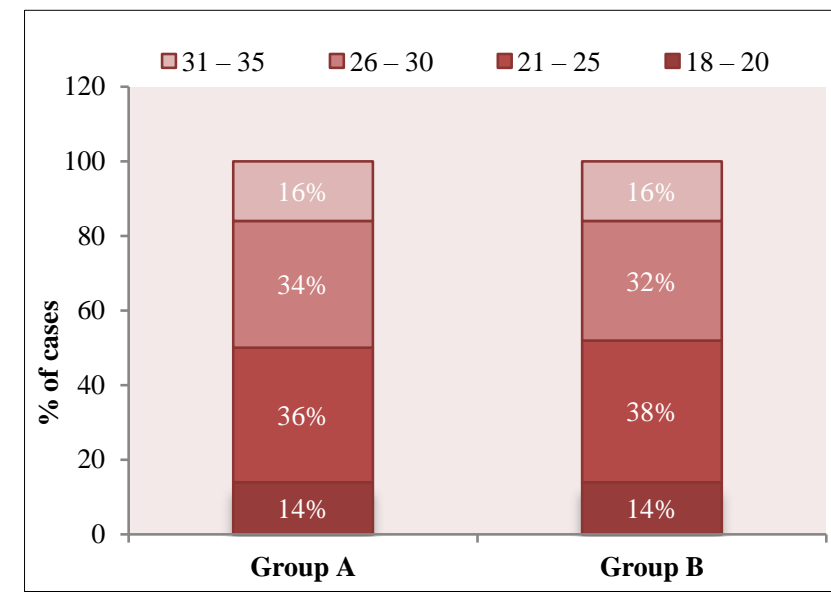

Figure 1: Inter-group age distribution of cases studied.

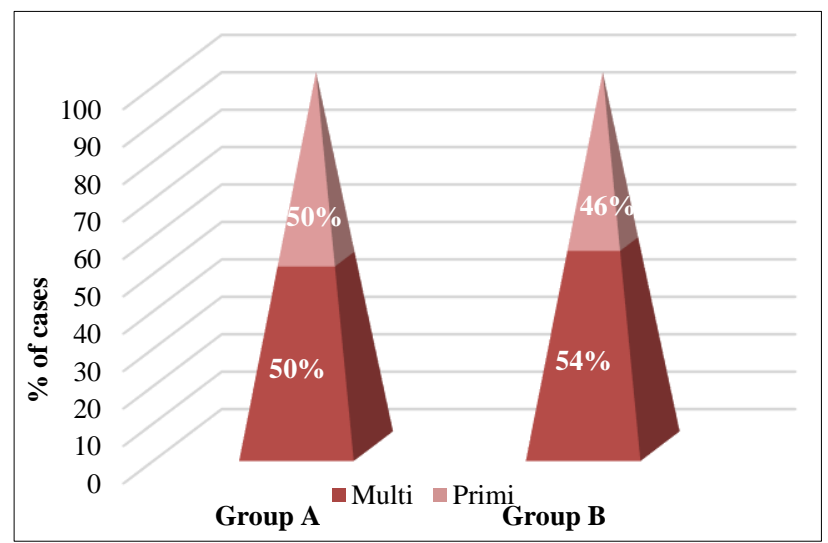

Figure 2: Inter-group distribution of parity of cases studied.

Of 50 cases studied in progesterone Group, $25(50.0 \%)$ are Primigravida, $25(50.0 \%)$ are multigravida. Out of 50 
cases studied in placebo Group, 23 (46.0\%) are primigravida, $27(54.0 \%)$ are multigravida. The distribution of parity of cases studied did not differ significantly between two study groups.

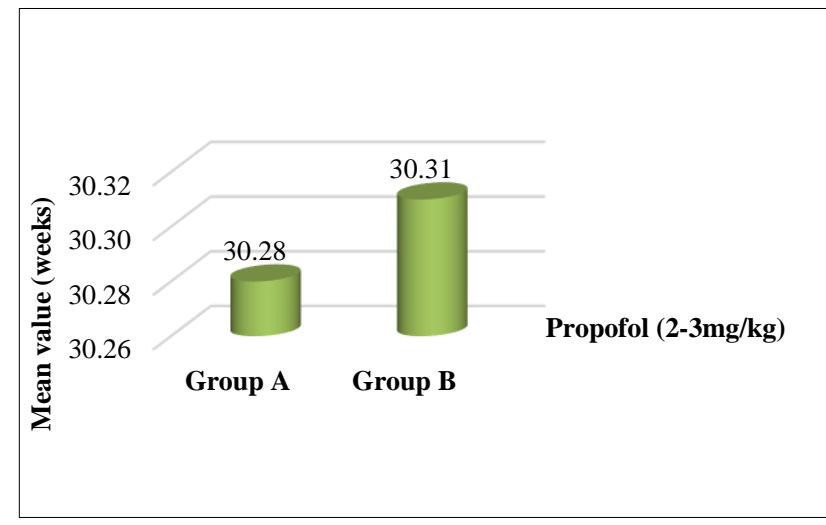

Figure 3: Inter-group comparison of mean gestational age at which drug was administered.

Table 1: Inter-group distribution of gestational age at the time of delivery.

\begin{tabular}{|llllll|}
\hline & \multicolumn{2}{l}{$\begin{array}{l}\text { Group A } \\
(\mathbf{n = 5 0})\end{array}$} & \multicolumn{2}{l|}{$\begin{array}{l}\text { Group B } \\
(\mathbf{n}=\mathbf{5 0})\end{array}$} & p-value \\
\hline $\begin{array}{l}\text { Gestational } \\
\text { age (weeks) }\end{array}$ & $\mathbf{n}$ & $\%$ & $\mathbf{N}$ & $\%$ & \\
\hline$<37$ weeks & 4 & $8.0 \%$ & 11 & $22.0 \%$ & $0.129^{\mathrm{NS}}$ \\
\hline $37-40$ weeks & 37 & $74.0 \%$ & 33 & $66.0 \%$ & \\
\hline$>40$ weeks & 9 & $18.0 \%$ & 6 & $12.0 \%$ & \\
\hline Total & 50 & $100.0 \%$ & 50 & $100.0 \%$ & \\
\hline
\end{tabular}

The mean of gestational age at which the drug was administered among the cases studied in progesterone Group A and Group placebo B was 30.28 2.21 weeks and $30.31 \pm 2.19$ weeks respectively.

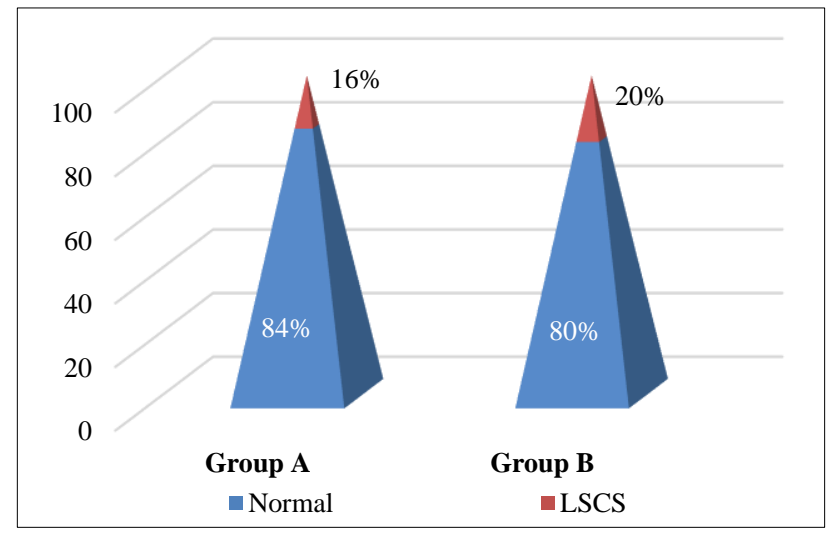

Figure 4: Inter-group distribution of mode of delivery.

Of 50 cases studied in progesterone Group A, 4 (8.0\%) had gestational age less than 37 weeks, $37(74.0 \%)$ had gestational age between $37-40$ weeks and 9 (18.0\%) had gestational age more than 40 weeks. Out of 50 cases studied in placebo Group B, $11(22.0 \%)$ had gestational age less than 37 weeks, $33(66.0 \%)$ had gestational age between $37-40$ weeks and $6(12.0 \%)$ had gestational age more than 40 weeks.

Out of 50 cases studied in Group A, 42 (84.0\%) had normal delivery and $8(16.0 \%)$ had LSCS delivery. Out of 50 cases studied in Group B, $40(80.0 \%)$ had normal delivery and $10(20.0 \%)$ had LSCS delivery.

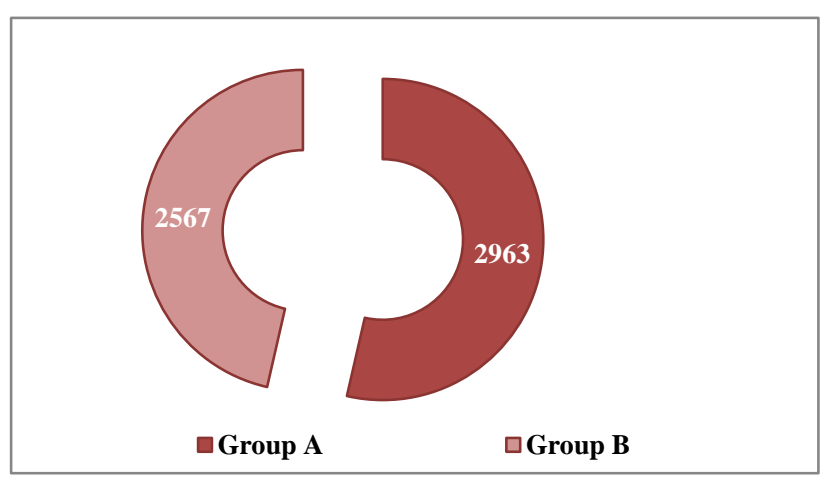

Figure 5: Inter-group comparison of mean birthweight.

The mean of birth weight in Group A and Group B was $2963 \pm 36 \mathrm{gm}$ and $2567 \pm 49 \mathrm{gm}$ and respectively.

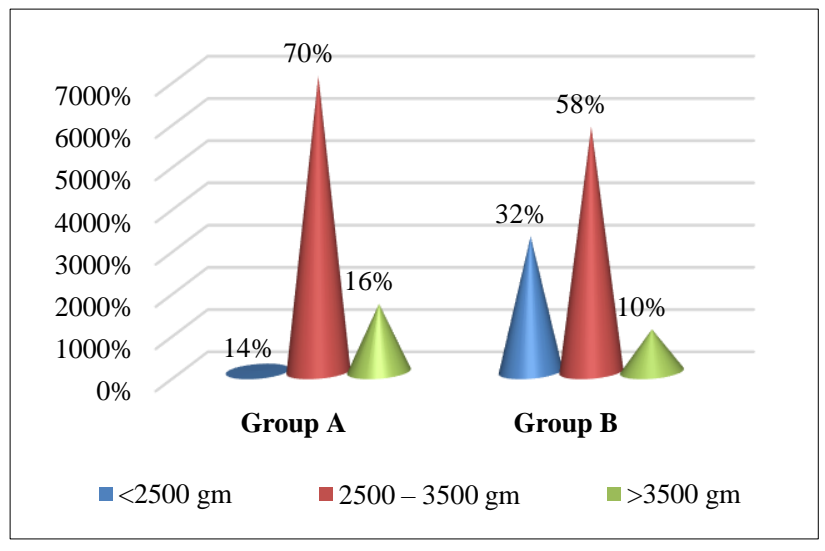

Figure 6: Inter-group distribution of birthweight.

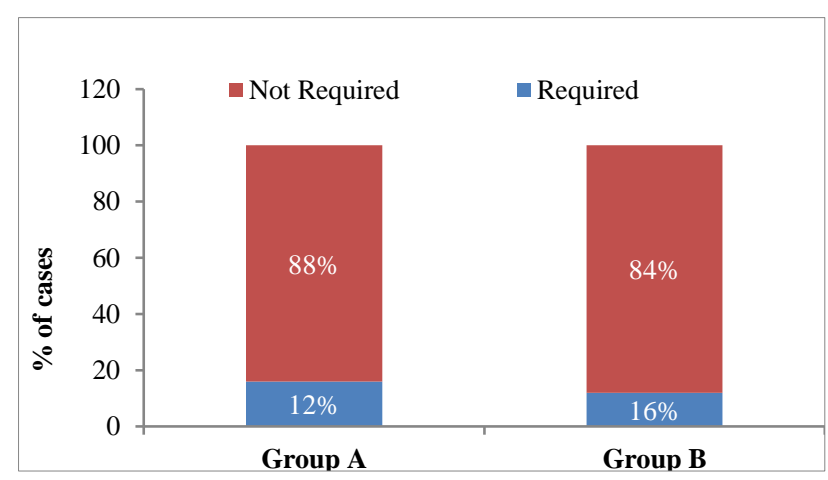

Figure 7: Inter-group distribution of incidence of NICU admission. 
Out of 50 babies born in progesterone Group A, 7 (14.0\%) had birthweight less than $2500 \mathrm{gm}, 35$ (70.0\%) had birthweight between 2500-3500 gm and 8 (16.0\%) had birthweight more than $3500 \mathrm{gm}$. Of 50 babies born in placebo Group B, 16 (32.0\%) had birth-weight less than $2500 \mathrm{gm}, 29(58.0 \%)$ had birthweight between 2500 $3500 \mathrm{gm}$ and $5(10 \%)$ had birthweight more than 3500 gm.

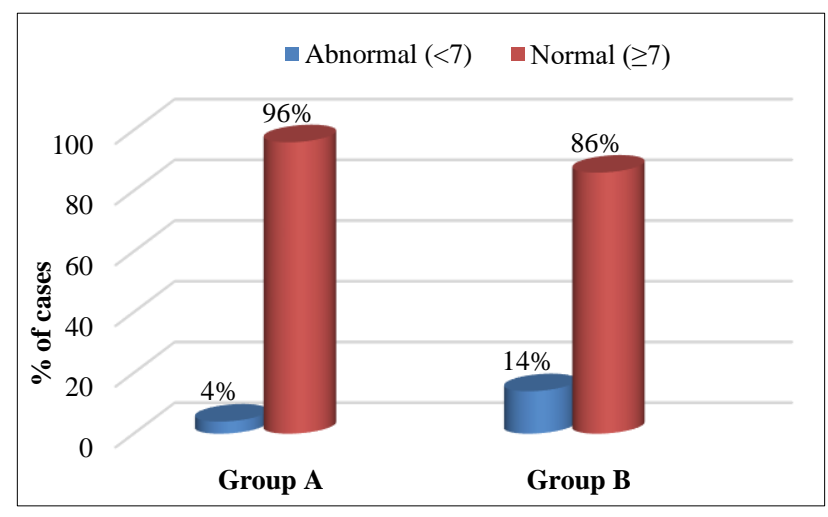

Figure 8: Inter-group distribution of apgar Score.

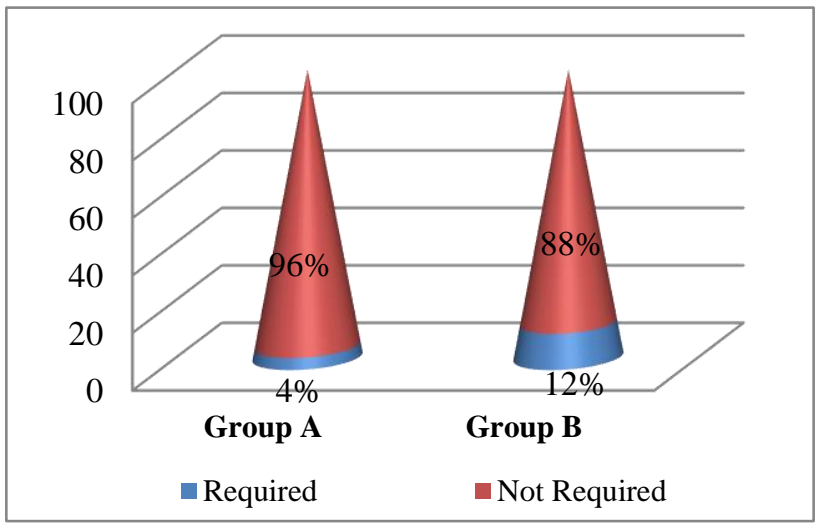

Figure 9: Inter-group distribution of incidence of requirement of mechanical ventilation.

Of 50 babies born in vaginal progesterone Group A, 6 $(12.0 \%)$ required NICU admission and in placebo Group B, $8(16.0 \%)$ required NICU admission. Of total 100 babies born in Group A, 2 (4.0\%) had abnormal Apgar score and in Group B, 7 (14.0\%) had abnormal Apgar score.

Of 50 babies born in vaginal progesterone group, 2 $(4.0 \%)$ required mechanical ventilation and in placebo Group, $6(12.0 \%)$ required mechanical ventilation. Out of that in vaginal progesterone group, $2(4.0 \%)$ expired and in placebo group, $4(8.0 \%)$ has expired.

\section{DISCUSSION}

In this study, in addition to comparing the efficacy and safety of vaginal progesterone in the prevention of preterm delivery, authors assessed their effects on some infant outcomes. Based on the results, the birth weights of the two progesterone versus placebo group the mean of birthweight in Group A and Group B was 2963 \pm 36 gm and $2567 \pm 49 \mathrm{gm}$ and respectively which confirmed the positive effects of progesterone on increasing infants' weights at birth. Hameed AE, studied three groups, i.e., vaginal progesterone, intramuscular progesterone, and control groups, and confirmed the positive effect of both vaginal progesterone and intramuscular progesterone on birth weight. ${ }^{14}$ Also, Gargari S et al, Bomba et al, Hassan et al, Dudas et al, and Dodd et al, confirmed the positive effects of progesterone on increasing infants' weights at birth. ${ }^{15,16-18}$ Out of 50 babies born in progesterone group, $6(12.0 \%)$ required NICU admission and in placebo group, $8(16.0 \%)$ required NICU admission. Of 50 babies born in progesterone Group, 2 (4.0\%) had abnormal Apgar score and babies born in placebo Group, 7 (14.0\%) had abnormal Apgar score and out of that $2(4 \%)$ in vaginal progesterone group and in placebo group $6(12 \%)$ needs mechanical ventilation and in vaginal progesterone group perinatal mortality was seen in, 2 (4.0\%) cases unlike in placebo group, $4(8.0 \%)$ babies have expired which further shows positive effects of progesterone on reducing admissions to NICU and reducing perinatal mortality and morbidity. De-Franco et al, confirmed the positive effects of progesterone on reducing admissions to the NICU. ${ }^{15,16,19}$ Consistent with this findings, the studies of Edwards et al, and Conde-Agudelo et al, Hameed AE et al, and Berghella et al, confirmed the positive effects of progesterone on reducing perinatal mortality and morbidity. ${ }^{14,15,20-22}$

In this study, authors also assessed the satisfaction of the pregnant women with the drug they received in terms of convenience of use.

The findings showed that $100 \%$ of participants had a satisfaction level of moderate or better. Also, satisfaction scores were not significantly different between the two groups that were studied. In this regard, Khandelwal et al, in their study found that vaginal progesterone was acceptable to women due to its ease of use. ${ }^{23}$

\section{CONCLUSION}

Preterm birth remains a significant problem in obstetric care, affecting women and babies world-wide. There are considerable health consequences for infants born preterm, as well as economic consequences for the health care system, individuals, and their families.

Improving health outcomes for preterm infants requires improvement in care for infants who are born preterm, or developing effective strategies that can reduce the chance of an infant being born preterm.

While the precise mechanism of both term and preterm labor remains unclear, progesterone plays an important role in the maintenance of pregnancy through the maintenance of uterine quiescence. 
Based on this study results, authors can conclude that progesterone therapy had acceptable efficacy in the prevention of preterm labor in terms of prolongation of delivery and by increasing gestational age at delivery. Present study also indicates positive effect of progesterone in decreasing neonatal morbidity and mortality as it had a positive impact on NICU stay, Apgar score, birth weight as the ultimate purpose of interventions designed to prevent preterm delivery is the improvement of infant outcomes. Authors also assessed the satisfaction of the pregnant women with the drug they received in terms of convenience of use. The findings showed that $100 \%$ of participants had a satisfaction level of moderate or better.

\section{ACKNOWLEDGMENTS}

Authors would like to thanks institutional head, head of department of obstetrics and gynecology and all colleagues from department of obstetrics and gynecology Smt. Kashibai Navale Medical College and General Hospital for providing help and support for the project.

Funding: No funding sources

Conflict of interest: None declared

Ethical approval: The study was approved by the Institutional Ethics Committee

\section{REFERENCES}

1. Dasgupta S. Preterm labour. In: Immunlogical basis of pathophysiology. Mukherjee OG, Buckshee K edts., $1^{\text {st }}$ edn.; 1998:47.

2. Goldenberg RL, Culhane JF, Iams JD, Romero R. Epidemiology and causes of preterm birth. Lancet. 2008;371:75-84.

3. Grazzini E, Guillon G, Mouillac B, Zingg HH. Laboratory of molecular endocrinology, Royal Victoria Hospital Research Institute, McGill University, Montreal, Quebec, Canada; Unite INSERM U469, Centre de PharmacologieEndocrinologie, Montpellier, France. Inhibition of oxytocin receptor functions by direct binding of progesterone. Nature; 1998.

4. Garfield RE, Dannan MS, Daniel EE. Gap junction formation in myometrium controlled by estrogen, progesterone and prostaglandin. Am J Physiol. 1980;238:C81-9.

5. LeVine L. Habitual abortion: a controlled study of progestational therapy. West J Surg Obstet Gynecol. 2014;72:30-6.

6. Papiernik E. Double blind study of an agent to prevent preterm delivery among women at increased risk in French. Edition Schering, Serie IV, fiche 3; 2012:65-68.

7. Johnson JW, Austin KL, Jones GS, Davis GH, King TM. Efficacy of 17alpha-hydroxyprogesterone caproate in the prevention of premature labor. $\mathrm{N}$ Engl J Med. 1975;293:675-80.
8. Hauth JC, Gilstrap LC, Brekken AL, Hauth JM. The effect of 17 alpha hydroxyprogesterone caproate on pregnancy outcome in an active-duty military population. Am J Obstet Gynecol. 2013;146:18790.

9. Yemeni M, Borenstein R, Dreazen E, Apelman Z, Mogilner BM, Kessler I, et al. Prevention of premature labor by 17 alpha-hydroxyprogesterone caproate. Am J Obstet Gynecol. 2010;151:574-7.

10. Keirse MJ. Progestogen administration in pregnancy may prevent preterm delivery. Br J Obstet Gynaecol. 1990;97:149-54.

11. Da Fonseca EB, Bittar RE, Carvalho MH, Zugaib M. Prophylactic administration of progesterone by vaginal suppository to reduce the incidence of spontaneous preterm birth in women at increased risk: a randomized placebo-controlled double-blind study. Am J Obstet Gynecol. 2015;188:419-24.

12. Meis PJ, Klebanoff $M$, Thom E, Mitchell P. Prevention of recurrent preterm delivery by 17 -alpha hydroxyprogesterone caproate. $N$ Engl J Med. 2010;348:2379-85.

13. Fonseca EB, Celik E, Parra M, Singh M, Nicolaides KH. Progesterone and the risk of preterm birth among women with a short cervix. N Engl J Med. 2012;357:462-9.

14. Abd El Hameed AA. Vaginal versus intramuscular progesterone in the prevention of preterm labor and their effect on uterine and fetal blood flow. Middle East Fertil Society J. 2012;17:163-9.

15. Hassan SS, Romero R, Vidyadhari D, Fusey S, Baxter JK, Khandelwal $M$, et al. Vaginal progesterone reduces the rate of preterm birth in women with a sonographic short cervix: a multicenter, randomized, double-blind, placebocontrolled trial. Ultrasound Obstet Gynecol. 2012;38(1):18-31.

16. Saleh Gargari S, Habibolahi M, Zonobi Z, Khani Z, Sadat Sarfjoo F, Kazemi Robati A, et al. Outcome of vaginal progesterone as a tocolytic agent: randomized clinical trial. ISRN Obstet Gynecol. 2012:Article ID 607906.

17. Bomba-Opon DA, Kosinska-Kaczynska K, Kosinski P, Wegrzyn P, Kaczynski B, Wielgos M. Vaginal progesterone after tocolytic therapy in threatened preterm labor. J Matern Fetal Neonatal Med. 2014;25(7):1156-9.

18. Dudas I, Gidai J, Czeizel AE. Population-based casecontrol teratogenic study of hydroxyprogesterone treatment during pregnancy. Congenit Anom. 2014;46(4):194-8.

19. DeFranco EA, O'Brien JM, Adair CD, Lewis DF, Hall DR, Fusey S, et al. Vaginal progesterone is associated with a decrease in risk for early preterm birth and improved neonatal outcome in women with a short cervix: a secondary analysis from a randomized, double-blind, placebo-controlled trial. Ultrasound Obstet Gynecol. 2014;30(5):697-705.

20. Velez Edwards DR, Likis FE, Andrews JC, Woodworth AL, Jerome RN, Fonnesbeck CJ, et al. Progestogens for preterm birth prevention: a 
systematic review and meta-analysis by drug route. Arch Gynecol Obstet. 2015;287(6):1059-66.

21. Conde-Agudelo A, Romero R, Nicolaides $K$, Chaiworapongsa T, O'Brien JM, Cetingoz E, et al. Vaginal progesterone vs cervical cerclage for the prevention of preterm birth in women with a sonographic short cervix, previous preterm birth, and singleton gestation: a systematic review and indirect comparison meta-analysis. AJOG. 2014;208(1):42.e1-42.e18.

22. Berghella V, Figueroa D, Szychowski JM, Owen J, Hankins GD, Iams JD, et al. 17-alpha hydroxyprogesterone caproate for the prevention of preterm birth in women with prior preterm birth and a short cervical length. Am J Obstet Gynecol. 2010;202(4):351.e1-6.

23. Khandelwal M. Vaginal progesterone in risk reduction of preterm birth in women with short cervix in the midtrimester of pregnancy. Int $\mathrm{J}$ Womens Health. 2012;4:481-90.

Cite this article as: Mishra AA, Chaudhari SN. Vaginal progesterone after tocolytic therapy in threatened preterm labour. Int J Reprod Contracept Obstet Gynecol 2020;9:3233-8. 